\title{
Some Inadequacies Of The Current Human Factors Certification Process Of Advanced Aircraft Technologies
}

\author{
Jean Paries \\ Bureau Enquêtes Accidents
}

\section{Introduction}

Automation related accidents or serious incidents are not limited to advanced technology aircraft. There is a full history of such accidents with conventional technology aircraft. However, this type of occurrence is far from sparing the newest "glass cockpit" generation, and it even seems to be a growing contributor to its accident rate. Nevertheless, all these aircraft have been properly certificated according to the relevant airworthiness regulations. Therefore, there is a growing concern that with the technological advancement of air transport aircraft cockpits, the current airworthiness regulations addressing cockpit design and human factors may have reached some level of inadequacy. This paper reviews some aspects of the current airworthiness regulations and certification process related to human factors of cockpit design and focuses on questioning their ability to guarantee the intended safety objectives.

\section{Current Certification Principles}

\section{Certification Purposes and References}

According to Article 31 of the Convention on International Civil Aviation (Chicago, 1944), any aircraft involved in international operation shall hold a certificate of airworthiness delivered or validated by its state of registry. This is intended to achieve protection of other aircraft, third persons and ground property while an aircraft registered in state B flies into or over the territory of state A. Following article 33 of the Convention, Annex 8 to the Convention includes broad standards which define the minimum international basis for the recognition by states of certificates of airworthiness delivered or validated by other states. Furthermore, Annex 8 sets the minimum international degree of standardization called upon by article 37 of the Convention.

Human Factors Certification of Advanced Aviation Technologies Edited by J. A. Wise, V. D. Hopkin, and D. J. Garland

Copyright $\odot 1994$ Embry-Riddle Aeronautical University Press 
However, as a matter of fact, the main purpose of airworthiness certification has been the protection of the passengers and crewmembers for a long time. This is a much more demanding objective, which has been achieved trough the implementation of national codes of airworthiness containing the full scope of requirements considered necessary by the states to reach the target safety level.

Today, only two airworthiness codes form the potential reference for any transport category aircraft certification: the U.S. FAR 25, and the European JAR 25. Due to the pressure of a highly internationalized business, these two codes are only differentiated by minor differences, and can therefore be referred to as a single reference for the present discussion.

\section{Basic Principles}

The airworthiness requirements concerning the cockpit, as for any other subsystem of the aircraft, are not aiming at any "best possible" design, but they intend to specify the minimum objectives to be matched by an applicant design. This is a very basic principle of any certification.

As far as human factors in cockpit design and equipment are concerned, the minimum objectives currently set by the airworthiness code are more or less limited to the following:

- To guarantee that the minimum crew (i.e., after one crew member incapacitation) is still able to do the job without excessive workload or fatigue (FAR/JAR 25-1523)

- To provide the crewmembers with acceptable comfort and protection against outside conditions, so that they can do their job without excessive effort, concentration or fatigue (FAR/JAR 25-771)

- To provide the crew with a sufficient visibility to the outside (FAR/JAR 25-7)

- To minimize the risks of mistake in the controls use, particularly through a standardization of the shape and movements of the primary flight controls (FAR/JAR $25-777 ; 781)$

- To minimize ambiguities in the information displayed by the instruments (FAR/JAR $25-1303 ; 1321 ; 1322$ )

- To provide the crew with relevant alerting information about unsafe functioning states of any equipment or system, and to allow appropriate crew action (FAR/JAR 251309).

However, these generic requirements are completed by a set of "special conditions," adapted to the specifics of each particular aircraft. These special conditions may well include extensive and detailed requirements for systems like CRT display flight instruments.

\section{Demonstration of Compliance}

The methodology used to check the compliance of a proposed design with a relevant airworthiness requirement heavily depends on the explicit versus implicit nature of the requirement. 
Explicit requirements are directly expressed in terms of design characteristics. For example, FAR/JAR 25-781 quotes: "cockpit control knobs must conform to the general shape... in the following figures." In this case, the compliance of a proposed design is rather easy to check, and direct examination of descriptive material (drawings, scale models, mock-ups) can be used.

However, most of the human factors related issues are covered by implicit requirements, expressed in terms of general outcomes to be achieved. For example, FAR/JAR 25- 777 (a) quotes: "each cockpit control must be located to provide convenient operation and to prevent confusion and inadvertent operation".

In the later case, the methodology used to evaluate the ability of a proposed design to reach the objective obviously is the critical part of the certification process. A first possible source of difficulty is the interpretation of the regulatory objective itself. A second possible source of difficulty is the acceptable means of compliance with the (interpreted) objective. Consequently some regulatory requirements are complemented with advisory material, including interpretation guidelines and/or indications on acceptable means of compliance. Acceptable means of compliance more often than not are proven solutions, or sets of solutions, that have been shown by service history to be satisfactory.

\section{The Test Pilot Judgment Methodology}

As a matter of fact, one of the only tools currently in use to evaluate a new design human factors acceptability in a certification process is test pilot judgment. This judgment is based on regulatory and company test pilots comparative experience, following from actual or simulated flight exposure (several thousands of hours for major test programs) in the subject cockpit on the one hand, and previous experience with existing designs on the other hand. In other words, this judgment is based on extrapolations to the new design of expertise gained on the previous ones.

Furthermore, the certification process cannot wait until the first aircraft prototype is built to start up. No manufacturer would take the risk of becoming involved in such highly expensive development programs without reasonable guarantee that the projected designs are certifiable. Consequently new designs are submitted to regulatory authorities to get some "certifiability" agreement well before a prototype aircraft is built. In this situation, pilot judgment cannot be exercised in a real cockpit (real flight context) but has to be exercised in a mock-up or some other form of simulated environment.

At the end of major certification programs, certification authorities are nowadays calling for operational route proving programs. These programs are the occasion for evaluating the aircraft in an airline-type environment, including "natural" and artificially induced failures, with mixed crews being composed of airline pilots and manufacturer test pilots. They have included up to one hundred flights in one occasion.

\section{Discussion}

The history of automation related accidents or serious incidents (see accident/incident reports list in annex) includes conventional generation aircraft such as the Lockeed L-1011 Tristar, the 
McDonnell Douglas DC-10, and the Boeing B-747. This type of occurrence even seems to be a growing contributor to the newest "glass cockpit" generation accident rate. This may be an incentive to question the current human factors certification process of advanced technology aircraft.

The protection ability of a certification process depends on several factors, including, but not limited to:

- The adequacy of the requirements in expressing relevant safety objectives

- The adequacy of the compliance checking methodology in use.

As far as the human factors certification process of advanced technology aircraft is concerned, it seems that critics may be surprised by both of these aspects.

\section{Some Potential Biases in the Current Human Factors Certification Objectives}

Airworthiness codes and their objectives are not floating by themselves in the vacuum. They are embedded in a global aviation safety system, including components such as personnel certification (selection, training, proficiency checking), or operational procedures certification. The design and functional characteristics of this safety system reflect specific theories about risk and safety in the aviation transportation system. These theories are far from being mere rational constructions, consistent with all the available scientific evidences. They also are historical and social outcomes, conveying the current fears and faiths of the aviation community.

The cutting up of the different safety codes and their role distribution is a first indicator of the background safety approach. This is particularly perceptible with the human error question. On the one hand, it is widely claimed that pilot error is contributing to about 70 percent of air transport accidents. On the other hand, merely four paragraphs $(\$ 777,781,1303,1309)$ of the airworthiness code, out of 330 , explicitly or implicitly address pilot error. This one percent order score suggests an implicit assumption that pilot error is neither really associated with airworthiness nor a design concern, but is much more related to pilot certification and procedures and operational regulations. As a matter of fact, this is the prevailing theory in the airworthiness world, and all the publications of the human factors researchers have had little influence on it up to now, except perhaps for this ironical one: a shift as occurred from culpability-based theories (pilot should not make errors) to fatalism (errors are normal and will always occur, whatever the design - so let's reinforce cross-check procedures...and substitute automation for pilot action as far as possible).

A second illustration is offered by the workload assessment focus in the certification of the last ten years cockpit generation. Even with the same reference airworthiness code, large variations generally occur in the selection of items subject to specific attention in the certification process of different aircraft. Great departures from previous designs will normally be given a closer look. This is true for technical designs and for human factors aspects as well. The glass cockpit generation has progressively brought a drastic change to the previous pilot environment, including two-crew design, computer generated displays, sophisticated automated flight controls, and flight management computers. These changes presented a lot of challenges to pilots, such as autopilot active mode awareness, total energy awareness, crew communication, automation over-reliance, and computer interface problems. But in practice, one single question stands above everything else: the workload question. An ad hoc 
Presidential Commission was set up in the United States in 1980 to endorse the concept. Since then, much effort, research and flight test time have been spent for evaluation, rating and judgment of workload levels during certification programs for the purpose of minimum crew complement assessment.

At this point, it is rather difficult to elude some paradoxical feeling about the situation. On the one hand, great efforts are made about work load certification, but there is no real history of overload related accident on glass cockpit aircraft. This could be interpreted as the nice benefit of a particularly effective certification process on cockpit designs. Unfortunately, workload certification programs take place so late in the certification process that it is hard to imagine any significant change in the cockpit at this time, except for associated procedures. (It is not the intention here to minimize the importance of minimum crew evaluation, but only to suggest that its perceived importance is also subjective, crystallizing the socially highly sensitive skip to the two-crew cockpit.)

On the other hand, there is a history of automation related accidents, but far less efforts are devoted to the certification of the related design aspects since they are not really felt to be airworthiness matters.

\section{The Adequacy of the Compliance Checking Methodology}

As already stated previously, nearly the only tool currently in use in a certification process to evaluate the acceptability of a new design in terms of human factors is test pilot judgment. This judgment is based on extrapolations to the proposed new design of expertise gained on the previous ones. Furthermore, as new designs are submitted to regulatory authorities to get some "certifiability" agreement well before a prototype aircraft is built, it often has to be exercised in simulated environment.

This test pilot assessment methodology is by nature affected by some biases.

First, it is based on the assumption that the experience of test pilots on previous aircraft is transferable on the new one. This may not be true for great developments in human-machine interface design. Secondly test pilots are not a representative sample of the airline pilots population. They have a very specific knowledge of the aircraft, which leads to different mental models of the aircraft. They do not share the daily routine operations and the associated constraints, and therefore the cognitive processes involved at the crew/aircraft interface are very doubtfully the same for test pilots and for airline pilots. Furthermore, typical figures for the number of individuals involved is about ten or a few tens and the total exposure time about two thousand hours. This is to be compared to the frequency of the hunted critical events or combinations of events, which is more likely to be of the order of one per hundred thousand hours. And to make things worse, recent studies (Amalberti \& Wilbaux,1994) indicate that cognitive behaviors evolve a lot during the training process on glass cockpit aircraft, and that the average experience needed for the training process to reach a maturity stage and stabilize the cognitive behaviors is about 800 hours, or one and a half years. This is by far a figure that no test pilot will reach during a typical test period with a new type of aircraft. As a consequence, test pilot judgment will be exercised within a cognitive frame and the typical errors encountered in testing, which is significantly different from the average airline pilot situation.

Finally, an individual judgment, even from a test pilot, would only provide rather soft grounds to refuse a proposed design. 


\section{Conclusion}

The current aircraft airworthiness certification requirements addressing human factors issues are expressed in rather general terms, and they are subject to interpretation uncertainties. This leads to an increasing inconsistency between the certification requirements and the new types of human-machine interface problems brought in by the glass cockpit highly automated aircraft generation. Consequently, it seems that there is a need for a redefinition of the objectives of the human factors certification process.

The current evaluation process for the certification of human factors related aspects of cockpit design rely almost entirely on test pilot judgment. This method has proven satisfactory for the past years, although it is marred by several biases. However, the changes induced by the new design of the pilot-aircraft interface has recently increased the effects of these biases to a significant degree. Consequently, it seems that there is a need for the development of human factors assessment protocols to complement test pilot assessment methodology.

\section{References}

Amalberti, R. \& Wilbaux, F. (1994). Advanced automated glass cockpit certification:Wariness about human factors. In: J. A. Wise, V. David Hopkin, and D. J. Garland (Eds.), Human Factors Certification of Advanced Aviation Systems. Daytona Beach: Embry-Riddle Aeronautical University Press.

\section{Aircraft Accident/Incident Reports}

(1) Eastern Airlines flight 401, Lockeed L-1011, Miami, Florida, December 29, 1972. NTSB accident report no AAR/ 73-14.

(2) Aeromexico flight 945, Mc Donnel Douglas DC10-30, over Luxembourg, Europe, November 11, 1979. NTSB incident report no AAR/ 80-10.

(3) SAS flight 901, Mc Donnel Douglas DC10-30, New-York JFK, February 28, 1984. NTSB accident report no AAR/ 84-15.

(4) China Airlines flight 006, Boeing 747-SP, 300NM northwest of San Francisco, California, February 19, 1985. NTSB accident report no AAR/ 86-03.

(5) Indian Airlines, Airbus A320, Bangalore, India, February 14, 1990.

(6) British Midlands Airways, Boeing 737-400, East Midland, UK, January 8, 1989. AAIB accident report.

(7) Lauda Air , Boeing 767-300, near Bangkok, Thailand, May 26, 1991.

(8) Air Inter flight 148, Airbus A320, Strasbourg, France, January 20, 1992. Rapport préliminaire de la Commission d'Enquête, February 1992.

(9) Thai International Airways, Airbus A310-300, Katmandu, Nepal, July 31, 1992. Accident report by the nepalese investigation commission. 